\title{
A GENERAL FORM OF JORDAN'S INEQUALITIES AND ITS APPLICATIONS
}

\section{LING ZHU}

Abstract. In this work, the general form of Jordan's double inequalities:

$$
P_{2 N}(x)+\alpha\left(r^{2}-x^{2}\right)^{N+1} \leqslant \frac{\sin x}{x} \leqslant P_{2 N}(x)+\beta\left(r^{2}-x^{2}\right)^{N+1}
$$

are established, where $x \in(0, r], r \leqslant \frac{\pi}{2}, P_{2 N}(x)=\sum_{n=0}^{N} a_{n}\left(r^{2}-x^{2}\right)^{n}, a_{0}=\frac{\sin r}{r}, a_{1}=$ $\frac{\sin r-r \cos r}{2 r^{3}}, a_{n+1}=\frac{2 n+1}{2(n+1) r^{2}} a_{n}-\frac{1}{4 n(n+1) r^{2}} a_{n-1}, N \geqslant 0$ is a natural number, $\alpha=a_{N+1}$ and $\beta=\frac{1-\sum_{n=0}^{N} a_{n} r^{2 n}}{r^{2(N+1)}}$ are the best constants in inequalities above. The application of the result above give a new infinite series $(\sin x) / x=\sum_{n=0}^{\infty} a_{n}\left(r^{2}-x^{2}\right)^{n}$ for $0<|x| \leqslant r \leqslant \pi / 2$, the general improvement of Yang Le inequality, and a general form of Kober's double inequality.

Mathematics subject classification (2000): 26E60, 26D07, 33C10.

Key words and phrases: Lower and upper bounds; Jordan's inequalities; spherical Bessel functions; infinite series; Kober's double inequality.

\section{REFERENCES}

[1] D. S. Mitrinovic, Analytic inequalities, Springer-Verlag, 1970.

[2] F. QI, L.-H. CUI AND S.-L. XU, Some Inequalities Constructed by Tchebysheff's Integral Inequality, Mathematical Inequalities and Applications 4 (1999), 517-528.

[3] L. DEBnATH AND C. J. ZHAO, New Strengthened Jordan's Inequality and Its Applications, Mathematical Inequalities and Applications 16 (4) (2003), 557-560.

[4] L. ZHU, Sharpening of Jordan's Inequalities and Its Applications, Mathematical Inequalities and Applications, 9 (1) (2006), 103-106.

[5] G. D. Anderson, M. K. VAmanamurthy, And M. Vuorinen, Conformal Invariants, Inequalities, and Quasiconformal Maps, New York, 1997.

[6] G. D. Anderson, S.-L. QIU, M. K. VAmanamurthy, And M. Vuorinen, Generalized Elliptic Integral and Modular Equations, Pacific J.Math., 192 (2000), 1-37.

[7] M. Abramowitz, I. STEgun, Handbook of Mathematical Functions, U.S. National Bureau of Standards, Washington, DC, 1964.

[8] D. ZwILlinger, CRC Standard Mathematical Tables and Formulae, CRC Press, 1996.

[9] F. E. HARris, Spherical Bessel Expansions of Sine, Cosine, and Exponential Integrals, Applied Numerical Mathematics, 34 (2000), 95-98.

[10] J. L. Bastardo, S. Abraham Ibrahim, P. Fernfindez de Cordoba, J. F. Urchuegufa Scholzel, YU. L. RATIS, Evaluation of Fresnel Integrals Based on the Continued Fractions Method, Applied Mathematics Letters, 18 (2005), 23-28.

[11] C. J. ZHAO, Generalization and Strengthen of Yang Le Inequality, Math. Practice Theory (in Chinese), 4 (2000), 493-497.

[12] H. KoBER, Approximation by integral functions in the complex domain, Trans. Amer. Math. Soc. 56 (1944), 22. 
[13] F. QI, Refinements and extensions of Jordan's and Kober's inequalities, Gongke Shuxue (Journal of Mathematics for Technology) 12 (4) (1996), 98-102. (Chinese).

[14] F. QI AND Q.-D. HAO, Refinements and sharpenings of Jordan's and Kober's inequality, Mathematics and Informatics Quarterly 8 (3) (1998), 116-120. 